\title{
Characterization of Alkaline Treatment and Fiber Content on the Physical, Thermal, and Mechanical Properties of Ground Coffee Waste/Oxobiodegradable HDPE Biocomposites
}

\author{
Ming Yee Tan, Hoo Tien Nicholas Kuan, and Meng Chuen Lee \\ Department of Mechanical and Manufacturing Engineering, Faculty of Engineering, Universiti Malaysia Sarawak, \\ 94300 Kota Samarahan, Sarawak, Malaysia \\ Correspondence should be addressed to Hoo Tien Nicholas Kuan; khtnicholas@unimas.my
}

Received 30 April 2017; Revised 28 June 2017; Accepted 13 July 2017; Published 27 August 2017

Academic Editor: Vijay K. Thakur

Copyright (C) 2017 Ming Yee Tan et al. This is an open access article distributed under the Creative Commons Attribution License, which permits unrestricted use, distribution, and reproduction in any medium, provided the original work is properly cited.

\begin{abstract}
Effect of alkali treatment on ground coffee waste/oxobiodegradable HDPE (GCW/oxo-HDPE) composites was evaluated using $5 \%, 10 \%, 15 \%$, and $20 \%$ volume fraction of GCW. The composites were characterized using structural (Fourier transform infrared spectroscopy (FTIR) and scanning electron microscopy (SEM)), thermal (thermogravimetric analysis (TGA) and differential scanning calorimetry (DSC)), mechanical (tensile and impact test) properties, and water absorption. FTIR spectrum indicated the eradication of lipids, hemicellulose, lignin, and impurities after the treatments lead to an improvement of the filler/matrix interface adhesion. This is confirmed by SEM results. Degree of crystallinity index was increased by $5 \%$ after the treatment. Thermal stability for both untreated and treated GCW composites was alike. Optimum tensile result was achieved when using $10 \%$ volume fraction with enhancement of $25 \%$ for tensile strength and $24 \%$ for tensile modulus compared to untreated composite. Specific tensile strength and modulus had improved as the composite has lower density. The highest impact properties were achieved when using $15 \%$ volume fraction that lead to an improvement of $6 \%$. Treated GCW composites show better water resistance with $57 \%$ improvement compared to the untreated ones. This lightweight and ecofriendly biocomposite has the potential in packaging, internal automotive parts, lightweight furniture, and other composite engineering applications.
\end{abstract}

\section{Introduction}

The environmental impact on agriculture waste from beverage process is an increasing worldwide concern. Upon preparation of coffee beverage, there is approximately $50 \%$ of the coffee beans remain as waste after processing. The consumption of coffee beverage around the world has led to a huge amount of ground coffee waste (GCW). It is reported that the annual production of the waste is 6 million tons worldwide [1]. Malaysia has a population of approximately 30 million and the coffee consumption is about 800 grams per capita [2]. GCW is an underutilized high nutrient and energy material as it contains large amount of organic compound which are fatty acid, lignin, cellulose, hemicelluloses, and other polysaccharides [3]. The existence of high content organic material and compound from the GCW has adverse environmental effect. The disposal of the GCW should be properly managed in order to turn it into value-added products. GCW has been used for biofuel production [4], as source of sugar [5], as precursor for production of activated carbon $[6,7]$, as compost [8], and as absorbent for metal ions removal [9]. Previous work done on modified ground coffee waste showed enhancement of mechanical properties compared to untreated ground coffee waste composite [10-12].

Alkaline treatment is a process where natural fiber is immersed in a strong aqueous solution, such as $\mathrm{NaOH}, \mathrm{LiOH}$, or $\mathrm{KOH}$ to create great swelling with resultant changes in the fine structure, dimension, morphology, and mechanical properties [13]. The surface treatment disrupts the hydrogen bonding in the network, which thereby increases the surface roughness and yields better mechanical interlocking and increases the amount of cellulose exposed on the fiber surface, thus increasing the number of possible reaction sites for coupling. Arrakhiz et al. [14] reported that the tensile strength decreased while tensile modulus increased with increasing particle loading of alfa, coir, and bagasse from 0 to $30 \mathrm{wt} \%$. Fávaro et al. [15] studied rice husk/postconsumer 
TABLE 1: Summary of the composites investigated in this study.

\begin{tabular}{|c|c|c|c|c|}
\hline Composite & Sample & Stacking sequence & Volume of GCW (\%) & Volume of oxo-HDPE (\%) \\
\hline $\mathrm{A} 1$ & oxo-HDPE (PE) & $150 \mathrm{PE}$ & 0 & 100 \\
\hline $\mathrm{B} 1$ & Untreated GCW5/oxo-HDPE & $150 \mathrm{PE}+5 \mathrm{UG}$ & 5 & 95 \\
\hline B2 & Untreated GCW10/oxo-HDPE & $150 \mathrm{PE}+10 \mathrm{UG}$ & 10 & 90 \\
\hline B3 & Untreated GCW15/oxo-HDPE & $150 \mathrm{PE}+15 \mathrm{UG}$ & 15 & 85 \\
\hline B4 & Untreated GCW20/oxo-HDPE & $150 \mathrm{PE}+20 \mathrm{UG}$ & 20 & 80 \\
\hline $\mathrm{Cl}$ & 1\% NaOH1/oxo-HDPE & $150 \mathrm{PE}+10 \mathrm{NG}$ & 10 & 90 \\
\hline $\mathrm{C} 2$ & 1\% NaOH6/oxo-HDPE & $150 \mathrm{PE}+10 \mathrm{NG}$ & 10 & 90 \\
\hline $\mathrm{C} 3$ & 1\% $\mathrm{NaOH} 12 /$ oxo-HDPE & $150 \mathrm{PE}+10 \mathrm{NG}$ & 10 & 90 \\
\hline $\mathrm{C} 4$ & $1 \% \mathrm{NaOH} 24 /$ oxo-HDPE & $150 \mathrm{PE}+10 \mathrm{NG}$ & 10 & 90 \\
\hline D1 & 1\% NaOH5/oxo-HDPE & $150 \mathrm{PE}+5 \mathrm{NG}$ & 5 & 95 \\
\hline D2 & 1\% $\mathrm{NaOH} 10 /$ oxo-HDPE & $150 \mathrm{PE}+10 \mathrm{NG}$ & 10 & 90 \\
\hline D3 & 1\% $\mathrm{NaOH} 15 /$ oxo-HDPE & $150 \mathrm{PE}+15 \mathrm{NG}$ & 15 & 85 \\
\hline D4 & $1 \% \mathrm{NaOH} 20 /$ oxo-HDPE & $150 \mathrm{PE}+20 \mathrm{NG}$ & 20 & 80 \\
\hline
\end{tabular}

polyethylene composites; Anbukarasi and Kalaiselvam [16] studied on luffa/epoxy composites that showed similar trend with no significant positive tensile strength with mercerization treatment. Another researcher [17] reported the result of opposite trend by using grewia optiva fiber.

For impact test, although the strength of luffa fiber/epoxy improved with particle loading, it was still lower than the unfilled epoxy [16]. Alkaline treatment increased the surface roughness of the fiber and thus resulted in a better fiber/matrix adhesion. The discontinuity particle fiber reinforced epoxy had weakened the material as the homogeneity of the material was declined. In comparison to untreated fiber, alkaline treated fiber also resulted in better dispersion and stress transfer, thus improving the impact strength. Obasi et al. [18] reported that alkali treated oil palm press fiber reinforced epoxy exhibited the similar trend where impact strength improved with increasing particle loading. The treatment of oil palm press fiber improved the compatibility and promoted the ability to dissipate energy during fracture.

Recycle is encouraged for energy saving and resources. However, the cost involved in recycling is expensive such as the difficulty in separation of reinforcement and matrix and the mechanical properties of the recycled composite material are degraded. Thus, the present study work on biocomposite fabricated using GCW reinforced oxobiodegradable HDPE. This is a green composite as both the reinforcement and matrix will decompose completely after their useful time. The oxobiodegradable plastic used contains $2-3 \%$ of transition metals that catalyze the degradation process at the end of useful life in the presence of oxygen with no unwanted environment consequences. Furthermore, the use of GCW helps to recycle high volume of generated GCW in order to turn it into a value-added product, minimize ecological damage, and reduce the production cost. Therefore, this is potentially a new alternative to cater to the problem of waste management. The composites were made to investigate the effect of alkaline treatment with different volume fraction on physical, thermal, and mechanical properties and water absorption. The outcome expected is a cost effective and green product that can be applied in many engineering applications.

\section{Materials and Methods}

2.1. Materials. Commercial oxobiodegradable high density polyethylene (HDPE) (density $0.96 \mathrm{~g} / \mathrm{mL} @ 23^{\circ} \mathrm{C}$ ) polymer matrix was provided by Kuek \& Kueh, Malaysia. $\mathrm{NaOH}$ was used to treat GCW.

2.2. Fiber Preparation. The used ground coffee waste (GCW) (Arabica) was collected from local cafe. The raw materials were washed with distilled water and dried in the oven at $105^{\circ} \mathrm{C}$ for 24 hours to $1-2 \%$ moisture content. Sieved analysis was conducted by automatic shaker sieve up to $850 \mu \mathrm{m}$.

2.3. Fiber Treatment. GCW were treated with $1 \%$ concentration of $\mathrm{NaOH}$ solution $(0.25 \mathrm{M})$ for $1,6,12$, and 24 hours at room temperature. Treated GCW were washed with distilled water until it return to $\mathrm{pH}$ 7. After that, treated GCW were dried at $105^{\circ} \mathrm{C}$ for 24 hours in the oven to remove the moisture content.

2.4. Composite Preparation. Each composite was prepared by sieving GCW in between plies of oxo-HDPE films. The compounding of GCW and oxo-HDPE were placed in a mold, and the composite was hot pressed at $3 \mathrm{MPa}$ for approximately 15 minutes until it reached $150^{\circ} \mathrm{C}$. The hot press was switched off and the composite was left to cool to room temperature. Thirteen different composites were prepared. The stacking sequences of the composites are shown in Table 1. Composite type A is neat oxo-HDPE, type $\mathrm{B}$ is untreated GCW composites with different volume fraction, type $\mathrm{C}$ is $1 \%$ concentration $\mathrm{NaOH}$ treated GCW composites at various treatment time with $10 \%$ volume fraction, and type $\mathrm{D}$ is $1 \%$ concentration $\mathrm{NaOH}$ treated GCW composites for 24 hours with different volume fraction.

2.5. FTIR. The untreated and treated GCW were analyzed using Fourier transform infrared spectroscopy (FTIR) using an IRAffinity-1 from Shimadzu. Each sample was subjected to 20 scans in the range of $600-4000 \mathrm{~cm}^{-1}$.

2.6. TGA. The untreated and treated GCW composites were undergone thermogravimetric analysis via Netzsch TG 200 F3 Tarsus. The temperature range used was from $30^{\circ} \mathrm{C}$ 
to $600^{\circ} \mathrm{C}$, at a heating rate of $10^{\circ} \mathrm{C} \mathrm{min}^{-1}$ under nitrogen atmosphere.

2.7. DSC. The untreated and treated GCW composites were analyzed using differential scanning calorimetry (DSC), Perkin Elmer equipment DSC 8000 model. Heating temperatures were from $50^{\circ} \mathrm{C}$ to $180^{\circ} \mathrm{C}$ at a rate of $20^{\circ} \mathrm{C} / \mathrm{min}$ in nitrogen atmosphere. The degree of crystallinity, $x_{c}$, was determined using

$$
\text { degree of crystallinity, } x_{c}(\%)=\frac{\Delta H_{m}}{\Delta H^{0}{ }_{m} \times w} \times 100 \%,
$$

where $\Delta H_{m}$ is the heat of fusion of GCW/oxo-HDPE composite, $\Delta H^{0}{ }_{m}$ is the theoretical heat of fusion of $100 \%$ crystallinity HDPE $\left(290 \mathrm{Jg}^{-1}\right)$ [19], and $w$ is the volume fraction of oxo-HDPE in the composite.

2.8. SEM. All the composites were investigated using a table top SEM (Hitachi TM3030) with $15 \mathrm{kV}$ electron with coating.

\subsection{Testing}

2.9.1. Tensile. Tensile properties were conducted using a Shimadzu universal testing machine model AG-300K IS MS. Tensile tests were carried out in accordance with ASTM D3039 at a crosshead displacement rate of $1 \mathrm{~mm} / \mathrm{min}$. Five different samples were subjected to tensile test [20].

2.9.2. Impact. Dart drop impact properties were characterized using Instron $9250 \mathrm{HV}$ in accordance with ASTM D3763-15. A $12.88 \mathrm{~mm}$ hemisphere head with $3.5 \mathrm{~kg}$ was employed. The velocity was recorded at $3.13 \mathrm{~m} / \mathrm{s}$ with initial drop height at $0.50 \mathrm{~m}$. Five different samples were subjected to impact test. The composites were tested to assess the resistance to falling weight [21].

2.10. Water Absorption. Water absorption test was conducted in accordance with ASTM D570-98. Test specimens were in the size of $76.2 \mathrm{~mm} \times 25.4 \mathrm{~mm}$. The specimens were immersed entirely in a container of distilled water at temperature $23 \pm 1^{\circ} \mathrm{C}$. The specimens were weighed after 2 hours. This process was repeated every 24 hours after that. The specimens shall be removed from the water one at a time. All the samples were wiped with a dry cloth immediately and weighed to the nearest $0.001 \mathrm{~g}$. Percentage of water absorption was measured by the following [22]:

$$
\begin{gathered}
\text { Percentage of water absorption, } \% \\
=\frac{W_{\text {final }}-W_{\text {initial }}}{W_{\text {initial }}} \times 100 \%,
\end{gathered}
$$

where $W_{\text {final }}$ is the final weight at certain immersion period and $W_{\text {initial }}$ is the initial weight of the sample before immersion.

\section{Results and Discussion}

3.1. FTIR. Figure 1 represents the FTIR spectra of untreated and treated GCW. Peaks in the range of $3000-3600 \mathrm{~cm}^{-1}$ and $600-1500 \mathrm{~cm}^{-1}$ showed the absorption of $-\mathrm{OH}$ stretching region. As the treatment time increases from 0 to 24 hours,
TABLE 2: Summary of TGA data of composites types A1, B2, and D2.

\begin{tabular}{lcccc}
\hline Composites & $T_{\text {onset }}\left({ }^{\circ} \mathrm{C}\right)$ & $T_{\max }\left({ }^{\circ} \mathrm{C}\right)$ & $T_{\text {final }}\left({ }^{\circ} \mathrm{C}\right)$ & Residue $(\%)$ \\
\hline A1 & 461.8 & 474.4 & 493.2 & 15.13 \\
B2 & 460.4 & 481.9 & 492.4 & 25.80 \\
D2 & 462.0 & 482.6 & 493.1 & 16.76 \\
\hline
\end{tabular}

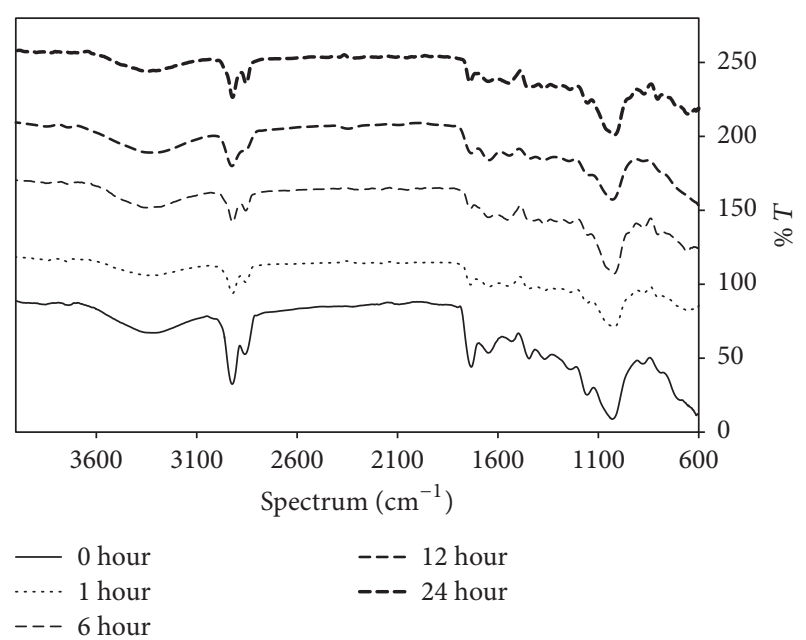

FIGURE 1: FTIR spectra of different time of $1 \% \mathrm{NaOH}$ treated GCW.

both $3100-3600 \mathrm{~cm}^{-1}$ and $600-1500 \mathrm{~cm}^{-1}$ regions exhibited a higher intensity with the presence of a higher $-\mathrm{OH}$ intensity on GCW. This contributed to more active sites interaction between GCW and oxo-HDPE matrix. During mercerization, cellulose I changed to cellulose II [23]. Untreated GCW was having a peak at $3351 \mathrm{~cm}^{-1}$ that is cellulose $\mathrm{I}, \mathrm{O}(3) \mathrm{H}-\mathrm{O}(5)$ bonds. Cellulose II was 3307, 3311, and $3319 \mathrm{~cm}^{-1}$ (OH inter$\mathrm{H}$-bond and $\mathrm{OH}$ intra-H-bond) presence after treatment [24]. Two peaks of 2859 and $2923 \mathrm{~cm}^{-1}$ represented the existence of the methyl and methylene group that was attributed to asymmetric and symmetric stretching of $\mathrm{C}-\mathrm{H}$ bonds in aliphatic chains. These peaks have been previously identified in roasted Arabica and Robusta coffee [25] and roasted coffee husks [26] and attributed to the presence of caffeine [27, 28]. The same peaks have been recognized as the presence of the lipids in corn and corn flour sample [29]. Highly soluble caffeine has been extracted upon preparation of coffee beverage. Thus, these peaks can be attributed to large amount of lipids in coffee sample. After alkaline treatment, the area of the two peaks were reduced since the lipid had been reduced. The characteristic of GCW peak at 1728 and $1651 \mathrm{~cm}^{-1}$ showed decreasing in bands after the treatment. These peaks were attributed to the acyl ester hemicellulose, aldehyde lignin, or carbonyl lipid $[25,30]$. The reduction of hemicellulose and lignin content is evident from the decreasing in $1250 \mathrm{~cm}^{-1}$ bands compared with untreated GCW. Peaks in the range of $1020-1026 \mathrm{~cm}^{-1}$ represented cellulose [31]. These peaks show higher intensity after treatment.

3.2. TGA. Figure 2 and Tables 2 and 3 show the TGA and DTG curves and summary data of composites types $\mathrm{A1}, \mathrm{B} 2$, and D2. As shown in Figure 2(a), the first step degradation was found at approximately $250^{\circ} \mathrm{C}$, followed 
TABle 3: Degradation temperature (in ${ }^{\circ} \mathrm{C}$ ) of composites types $\mathrm{A} 1, \mathrm{~B} 2$, and D2.

\begin{tabular}{lcccc}
\hline Composites & $\begin{array}{c}\text { Temperature at 10\% weight } \\
\text { loss }\left({ }^{\circ} \mathrm{C}\right)\end{array}$ & $\begin{array}{c}\text { Temperature at 15\% weight } \\
\text { loss }\left({ }^{\circ} \mathrm{C}\right)\end{array}$ & $\begin{array}{c}\text { Temperature at 25\% weight } \\
\text { loss }\left({ }^{\circ} \mathrm{C}\right)\end{array}$ & $\begin{array}{c}\text { Temperature at 50\% weight } \\
\text { loss }\left({ }^{\circ} \mathrm{C}\right)\end{array}$ \\
\hline A1 & 456.52 & 462.48 & 469.74 & 479.60 \\
B2 & 422.11 & 450.39 & 464.64 & 478.01 \\
D2 & 431.32 & 451.88 & 464.96 & 478.52 \\
\hline
\end{tabular}

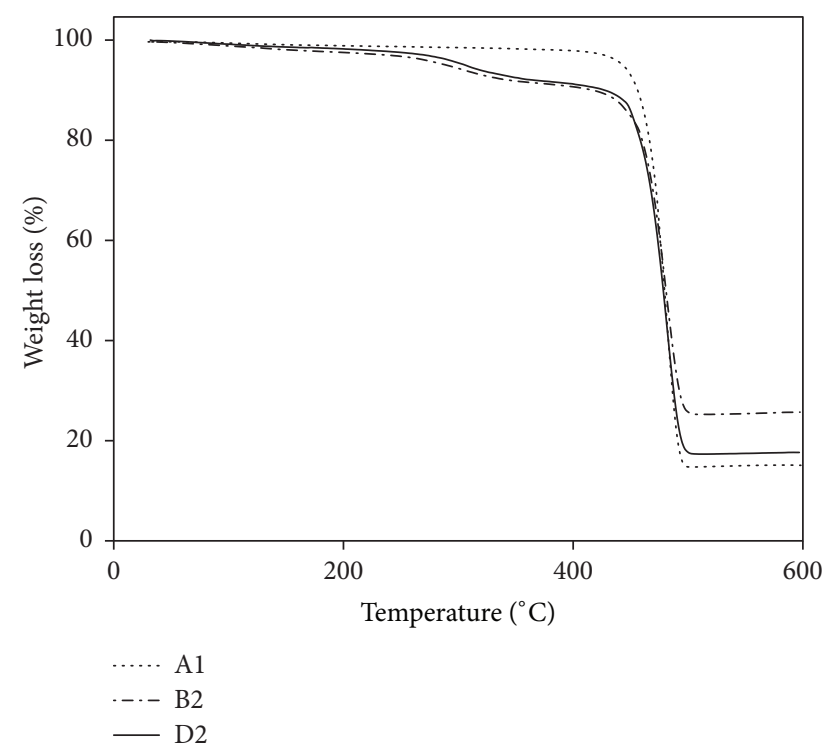

(a)

FIGURE 2: (a) Thermogravimetric analysis (TGA) thermogram. composites types A1, B2, and D2.

by second step at approximately $440^{\circ} \mathrm{C}$. Hemicellulose was found to decompose at a maximum of $290^{\circ} \mathrm{C}$, cellulose $370^{\circ} \mathrm{C}$, and lignin $280^{\circ} \mathrm{C}$ to $520^{\circ} \mathrm{C}[32,33]$. Therefore, the first step was due to the decomposition of pectin, wax, impurities, and hemicellulose, and second step was due to the decomposition of lignin and cellulose.

Figure 2(b) represents the peak of the main decomposition temperature of the composites or T max. Table 2 shows the initial degradation temperature (Tonset), maximum degradation temperature (Tmax), final degradation temperature (Tfinal), and mass residue of the tested composites for TGA. Tonset, Tmax, and Tfinal of the composites types B2 and $\mathrm{D} 2$ remained very close to composite type A1. Composite type B2 depicted the highest percentage of charred residue.

The temperature used for thermoforming HDPE was around 180 to $200^{\circ} \mathrm{C}$ [19] and lignocellulosic fibers were having complete thermal degradation above $400^{\circ} \mathrm{C}$ [31]. However, all of the composites were having high onset degradation temperature $\left(460^{\circ} \mathrm{C}-462^{\circ} \mathrm{C}\right)$. This shows that the incorporation of GCW reinforced oxo-HDPE improved the thermal stability of both the reinforcement and matrix.

Table 3 shows the percentage weight loss for composites types A1, B2, and D2. It could be detected from Table 3 that degradation of composite type $\mathrm{B} 2$ occurred earlier than the composite type $\mathrm{D} 2$. The $\mathrm{NaOH}$ treatment was able to increase the thermal stability of the composite. This was attributed to reduction of pectin, wax, hemicellulose, lignin,

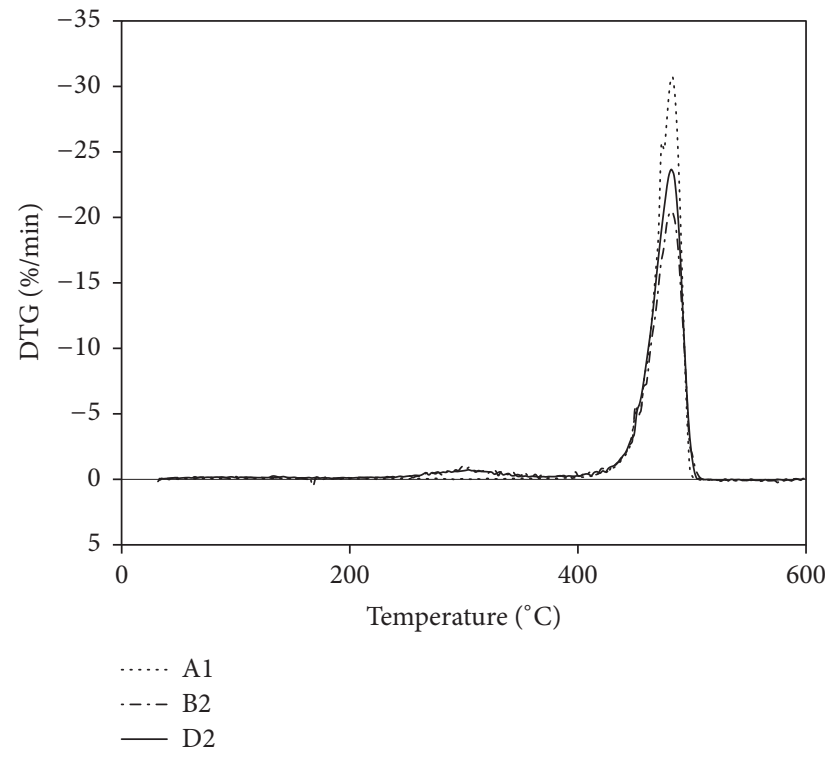

(b)

(b) Differential thermogravimetric graphics (DTG) thermogram of

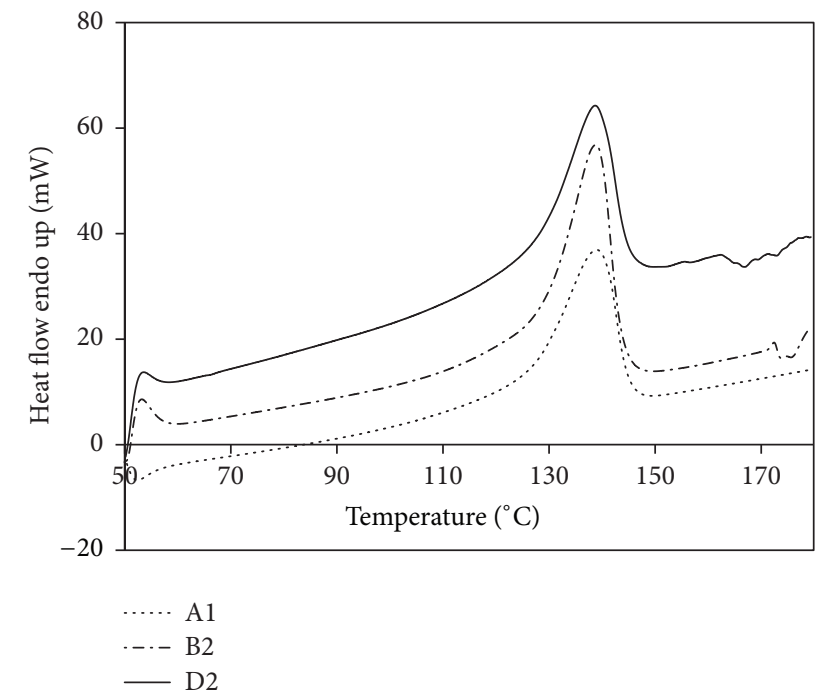

FIGURE 3: DSC curves of composites types A1, B2, and D2.

and impurities content after $\mathrm{NaOH}$ treatment as observed in the FTIR spectra (Figure 1).

3.3. DSC. Figure 3 depicts DSC curves of composites types $\mathrm{A} 1, \mathrm{~B} 2$, and D2 with endothermic peaks during the temperature scan, while Table 4 shows the summary data of 


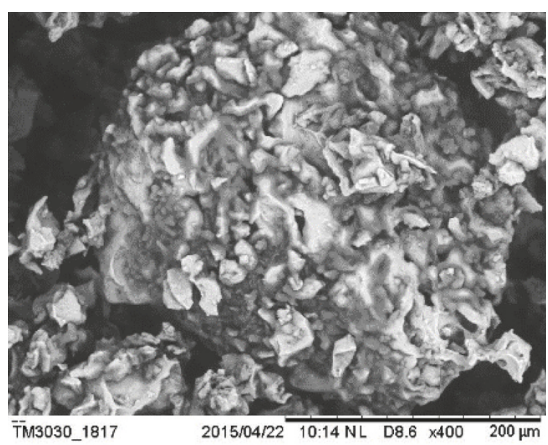

(a)

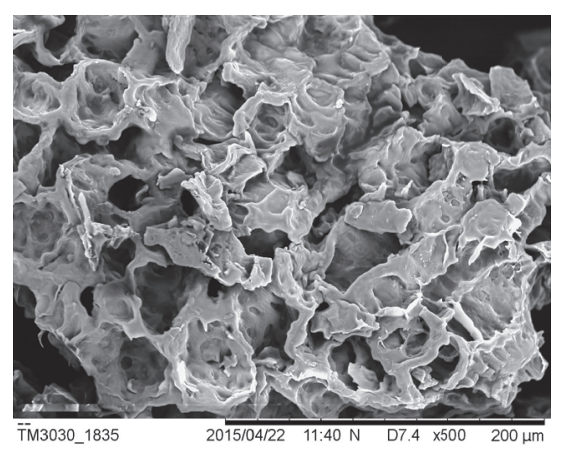

(b)

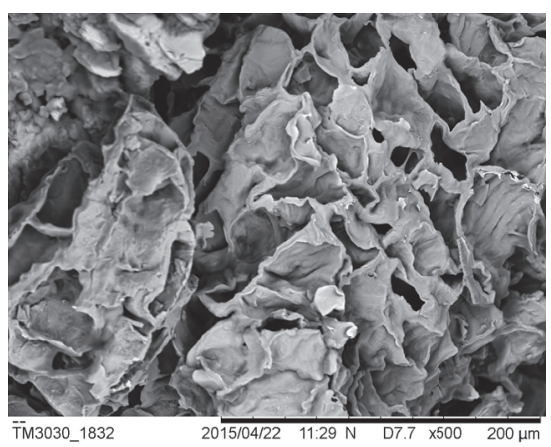

(c)

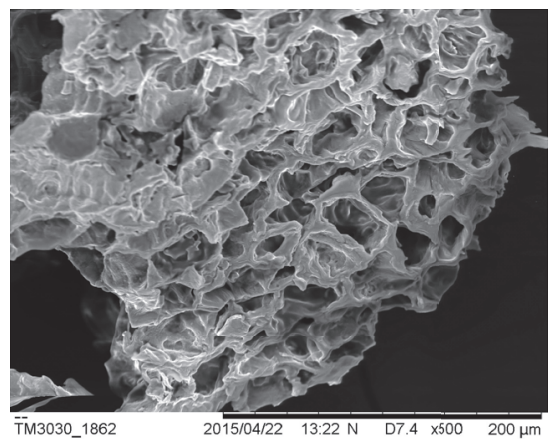

(d)

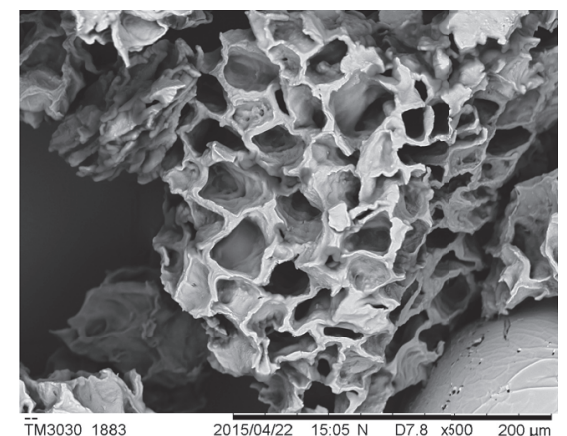

(e)

FIgURE 4: SEM image of (a) $0 \mathrm{hr}$, (b) $1 \mathrm{hr}$, (c) $6 \mathrm{hr}$, (d) $12 \mathrm{hr}$, and (e) $24 \mathrm{hr}$ of $1 \% \mathrm{NaOH}$ treated GCW.

TABLE 4: Summary of DSC data of composites types A1, B2, and D2.

\begin{tabular}{lccc}
\hline Composites & $T_{m}\left({ }^{\circ} \mathrm{C}\right)$ & $\Delta H_{m}(\mathrm{~J} / \mathrm{g})$ & $X_{c}(\%)$ \\
\hline $\mathrm{A} 1$ & 138.92 & 142.44 & 49.12 \\
$\mathrm{~B} 2$ & 138.85 & 133.27 & 51.06 \\
$\mathrm{D} 2$ & 139.69 & 140.05 & 53.66 \\
\hline
\end{tabular}

DSC. The peak of the curve represented crystalline melting temperature, $T_{m}$, of composites $\mathrm{A} 1, \mathrm{~B} 2$, and D3. $T_{m}$ were remained in the range of $138^{\circ} \mathrm{C}$ to $140^{\circ} \mathrm{C}$. Heat of fusion, $\Delta H_{m}$, was calculated using the area in Figure 3, while degree of crystallinity, $X_{c}$, was calculated using (1). As observed in Table 4 , the degree of crystallinity increased slightly with the inclusion of both untreated and treated GCW into the composite. This may be due to the nucleating ability of the GCW particle reinforcement for crystallization of oxo-HDPE [17]. For composite type D, $\mathrm{NaOH}$ treatment conducted had removed amorphous materials, such as hemicellulose and pectin, supported by FTIR (Figure 1) from the GCW surface [34] and, thus, increased the crystalline components in GCW and resulted in higher $X_{c}$ composites.

3.4. SEM. Figure 4 depicts the SEM images of untreated and $\mathrm{NaOH}$ treated GCW fillers with different treatment time. Untreated GCW was having a smoother surface in comparison to treated GCW. As the treatment time increased from 0 to $1,6,12$, and 24 hours, more uneven concave surfaces appeared as the impurities were removed. The impurities were hemicellulose, lignin, pectin, wax, and lipid as supported by both FTIR and TGA as discussed earlier.
As a consequence, the surface of GCW was actually getting rougher. The rougher surfaces were able to enhance the interfacial bonding between GCW particle/matrix.

Figure 5 illustrates the SEM images corresponding to tensile fracture surfaces of composites types B2 and C2. For composite type B2, gap can be seen on the fractured surface in between the untreated GCW and oxo-HDPE due to poor GCW particle/matrix adhesion. The adhesion between the GCW and oxo-HDPE composite was improved with $\mathrm{NaOH}$ treatment (composite type $\mathrm{C} 2$ ) as the rougher surface that led to a better impregnation of the matrix.

3.5. Tensile. Figure 6 shows tensile properties of composite type C. GCW were treated with $1 \%$ concentration of $\mathrm{NaOH}$ (0.25 molarity) with different treatment time $(0,1$, 6,12 , and 24 hours) for $10 \%$ volume fraction. The result revealed the tensile properties increase with treatment time. Tensile strength showed an improvement of $32 \%$, tensile modulus 23\%, specific tensile strength $42 \%$, and specific tensile modulus $32 \%$. The mercerization process removed surface impurities, natural fats, waxes, hemicellulose, and small amount of lignin from GCW [35]. This has increased the surface roughness of GCW as confirmed by FTIR and SEM result reported earlier and, thus, resulted in higher intensity of hydroxyl group and other reactive functional groups on the surface and provided more active sites interaction between reinforcement and matrix [36]. This suggested a better interaction and mechanical interlocking between $\mathrm{NaOH}$ treated GCW and oxo-HDPE matrix that yielded higher tensile properties. 


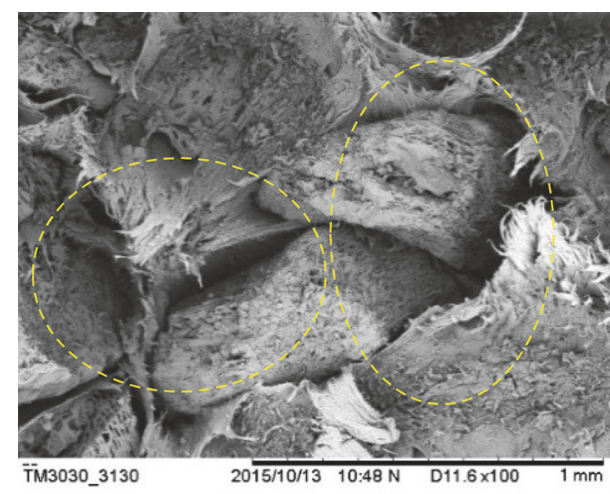

(a)

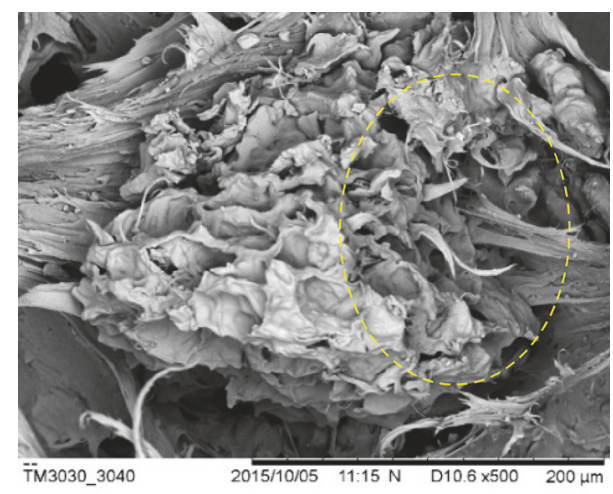

(b)

FIGURE 5: SEM image of breaking surface of composites types (a) B2 and (b) C2. The yellow circles in (a) are to show the gaps in between GCW/oxo-HDPE composites, poor adhesion and in (b) to show better adhesion between GCW/oxo-HDPE after treatment, better adhesion.

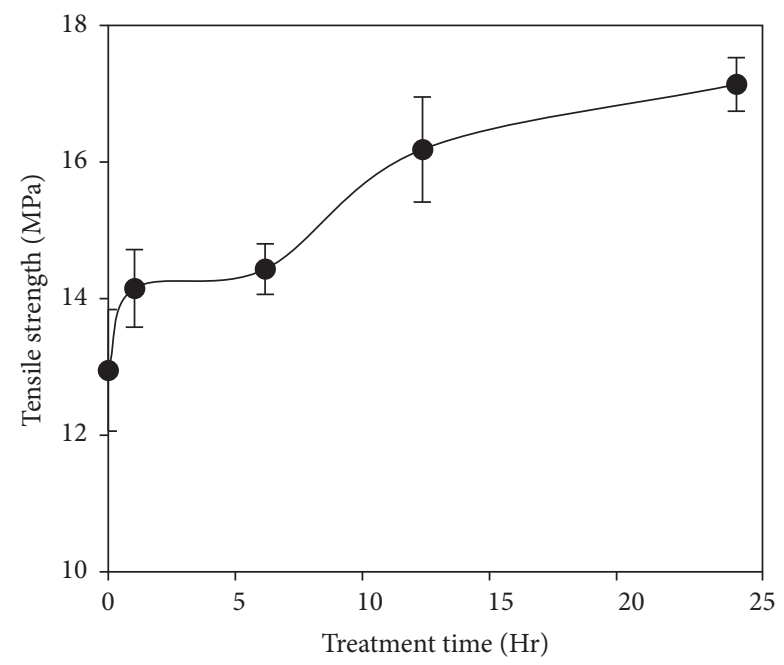

(a)

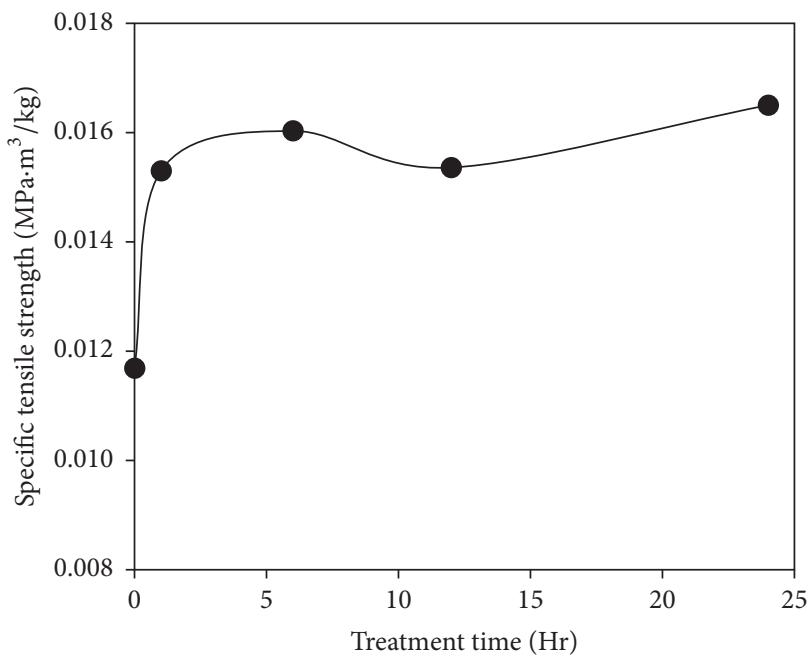

(c)

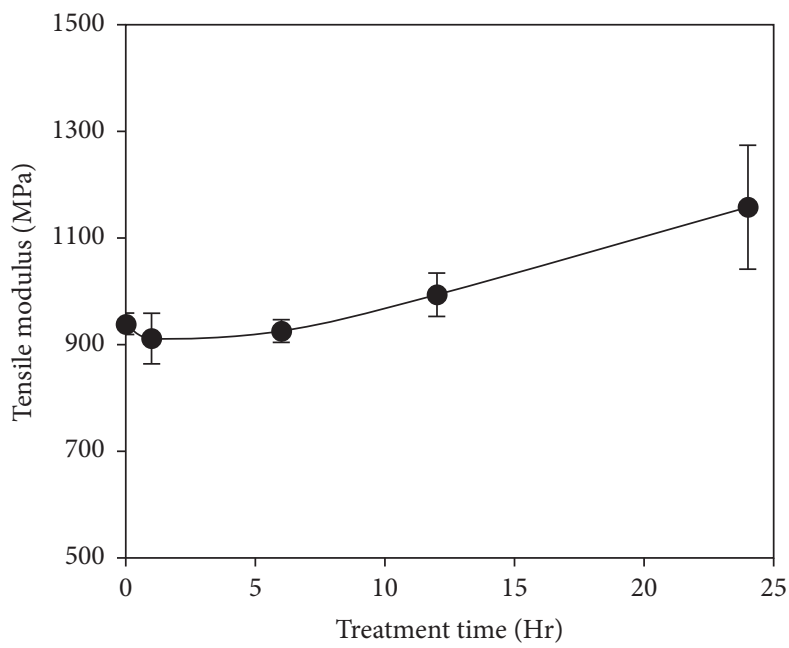

(b)

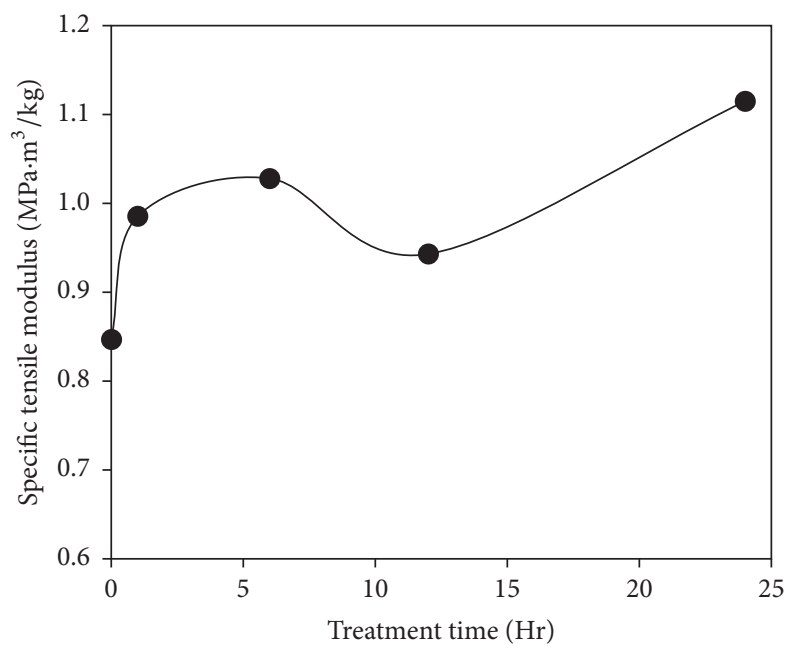

(d)

FIGURE 6: Effect of treatment time on (a) tensile strength, (b) tensile modulus, (c) specific tensile strength, and (d) specific tensile modulus of composite type C. 


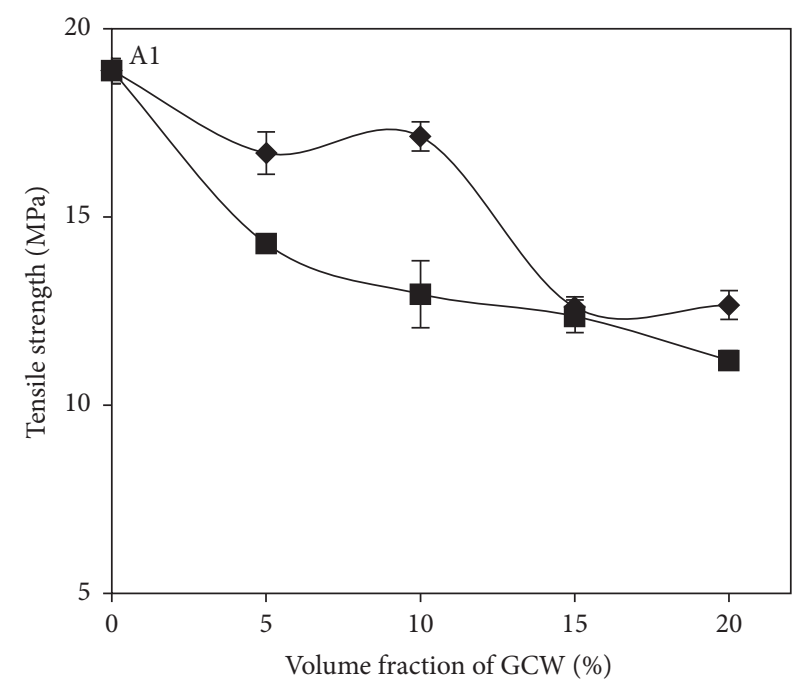

$-B$
$-D$

(a)

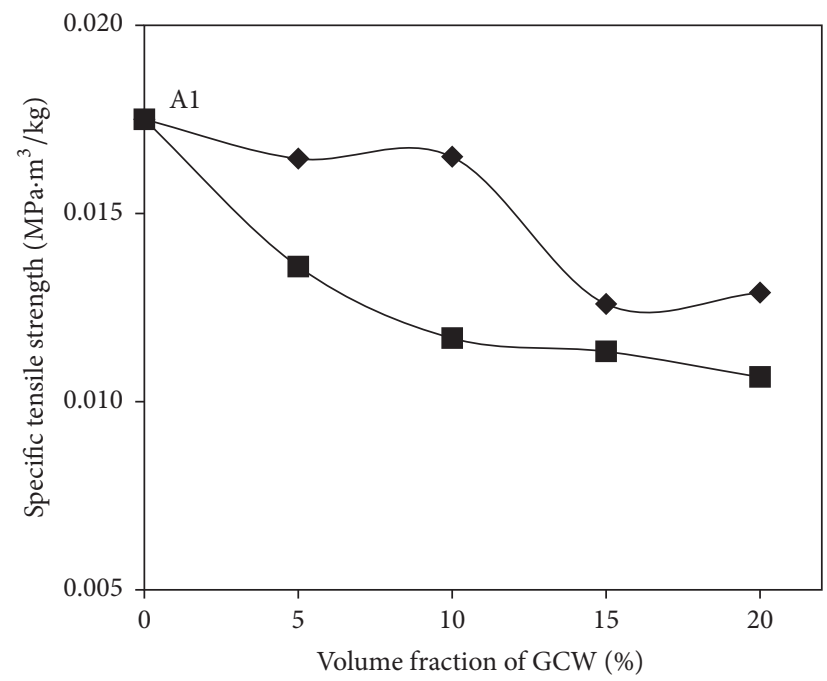

$\rightarrow B$
$-D$

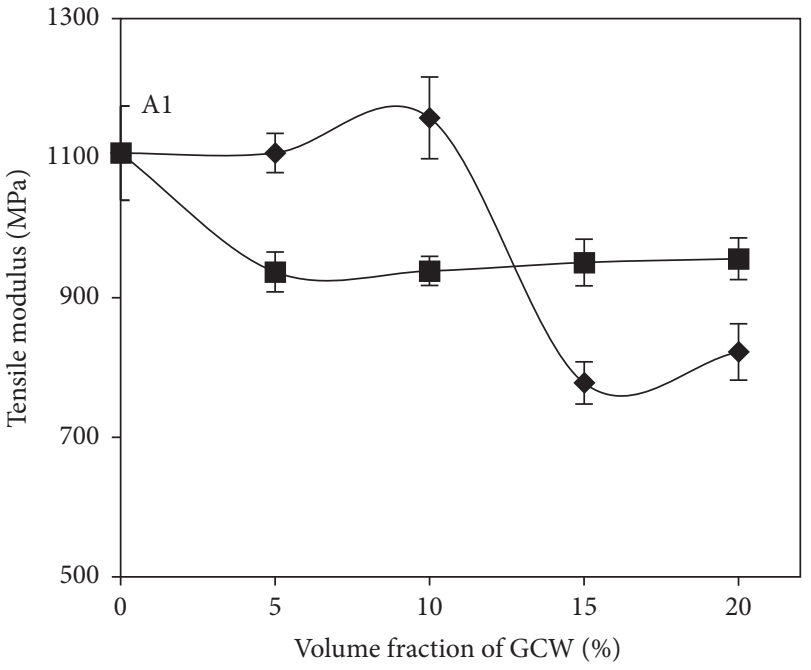

(b)

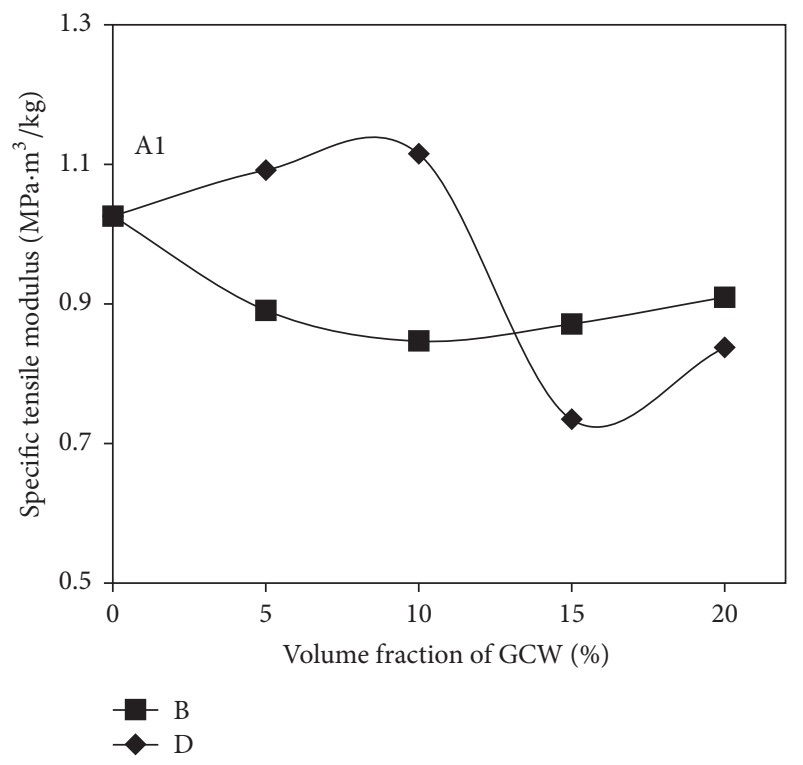

(d)

FiguRE 7: Effect of volume fraction of GCW on (a) tensile strength, (b) tensile modulus, (c) specific tensile strength, and (d) specific tensile modulus of composites types B and D.

Figure 7 illustrates tensile properties of composites types B (untreated GCW) and D (treated GCW) with different volume fraction of GCW $(0 \%, 5 \%, 10 \%, 15 \%$, and $20 \%)$. The tensile strength and modulus of the reference neat oxoHDPE were 18.89 MPa and 1107 MPa. After the inclusion of GCW, tensile strength deteriorated while tensile modulus improved slightly compared to neat oxo-HDPE. GCW with irregular cross section having low aspect ratio $(<2)$ might be the main concern of deteriorating properties [37]. Aspect ratio (length to diameter ratio) shows a greater effect on tensile properties than the particle size [38]. A high aspect ratio is expected, indicating the strength properties. It acts to control the fiber dispersion while improving the adhesion between fiber-matrix and optimizing the performance of the composites [39]. Composite type B showed a decreasing trend of tensile properties with increasing volume fraction. Poor interaction can be seen in between untreated GCW and oxoHDPE with a layer of impurities in SEM image (Figure 5(a)). For composite type D, tensile strength and tensile modulus were optimum when using $10 \%$ volume fraction. The highest tensile strength achieved was $17.14 \mathrm{MPa}$, an increment of $25 \%$, while tensile modulus was $1158 \mathrm{MPa}$, an increment of $24 \%$, compared to untreated GCW. In comparison to composite type A, the tensile modulus improved slightly by $5 \%$. The inclusion of GCW improved the stiffness of the composites. After the removal of hemicellulose, lignin, pectin, wax, and 


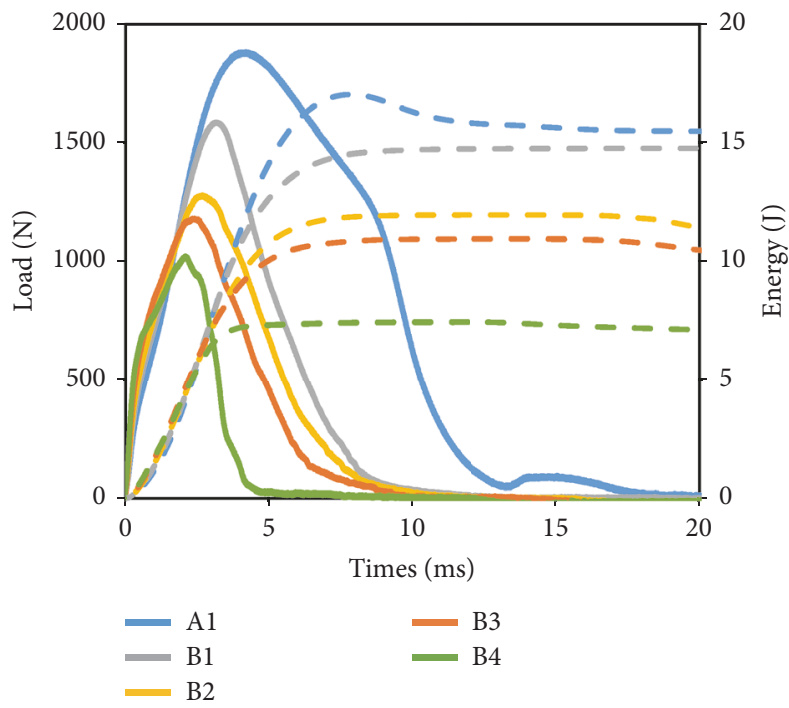

(a)

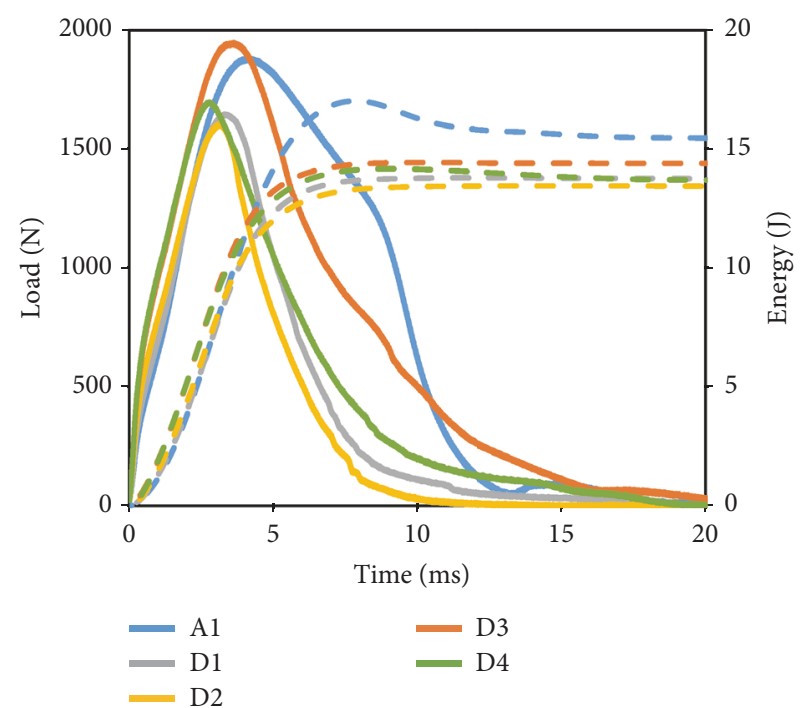

(b)

Figure 8: Load-energy-time graph of impact test: (a) composites types A and B; (b) composites types A and D.

impurities, the density and rigidity of interfibrillar region became less and were able to rearrange themselves along the direction of tensile deformation upon the applied load [35] and, thus, exhibited better tensile properties compared to composite type B. Increasing the volume fraction of GCW would lead to a decrease in tensile properties [40]. Too many GCW particles would tend to agglomerate and form bigger particle and cause a nonhomogenous dispersion. Big particles tend to debond easily and thus result in poor mechanical properties. Similar tensile results were obtained by other researchers [14-16, 37].

Figures 6(c), 6(d), 7(c), and 7(d) show the specific tensile strength and modulus that determine strength and stiffness to weight ratio. The specific tensile strength of composite type A was $0.0175 \mathrm{MPa} \cdot \mathrm{m}^{3} / \mathrm{kg}$ while composites types B and $\mathrm{D}$ showed lower specific tensile strength. On the other hand, the specific tensile modulus improved for 6 to $9 \%$ for composites types D1 and D2. The improvement in specific tensile properties was due to lighter weight of the composites. This contributed to reduction in $\mathrm{CO}_{2}$ emission that can bring about a lower weight in transportation, easier installation, and less maintenance in continuity of operation in industrial application. It is suitable to be used in the applications where weight is paramount, such as packaging applications, internal automotive parts, or lightweight furniture.

3.6. Impact. Figure 8 shows the load-energy-time graph of impact test while Figure 9 depicts load, energy to maximum load, and total energy absorbed by composites types A, B, and D. Impact test can be used to determine the amount of load, energy at maximum load, and total absorption energy of a specimen. The stiffness composites types $\mathrm{B}$ and $\mathrm{D}$ was improved compared to the composite type $\mathrm{A}$ as shown in the ascending part of the graph in Figure 8. Composite type D showed higher stiffness than composite type B. However, the maximum load that can be sustained by composite type B decreased with volume fraction. For composite type D, the maximum load can be sustained by the composite was at volume fraction of $15 \%$, an improvement of $6 \%$ compared to composite type A. Energy to maximum load is the energy absorbed by the samples with maximum load. It is the amount of energy that can be absorbed by a sample before failure. Results of energy to maximum load was showing similar trend to maximum load that can be sustained by the composites. The decreasing curve of the graphs after maximum load represented the material's property. The brittleness of the composites increased with volume fraction of GCW. On the other hand, the ductility behavior increased for composite type D. This can be explained in Figures 10 and 11, where the fracture surface showed that composite type $\mathrm{D} 3$ was having a tougher surface than composite type B3. The treated reinforcement exhibited better impact results as an outcome of better adhesion between reinforcement and matrix. The delamination of the composites occurred at the perforated area. The delamination area for composite type B3 was larger. The area of the graph is the total energy absorbed by the test specimens. The total energy absorbed by composite type B was decreased as the volume fraction of GCW increased. Total energy absorbed by the composite is the sum of the energy consumed during plastic deformation. After the inclusion of GCW, the composites became harder, brittle, and less ductile, so the total energy absorbed become lower compared to composite type A. In addition, less adherence in between hydrophilic GCW and hydrophobic oxo-HDPE leads to less energy absorption too. Total energy absorption increased with increasing treated GCW and reached its optimum condition at volume fraction of $15 \%$ (composite type D3). This is due to better interphase after the treatment as unwanted surface impurities had been removed and rougher surface and active sites were exposed 


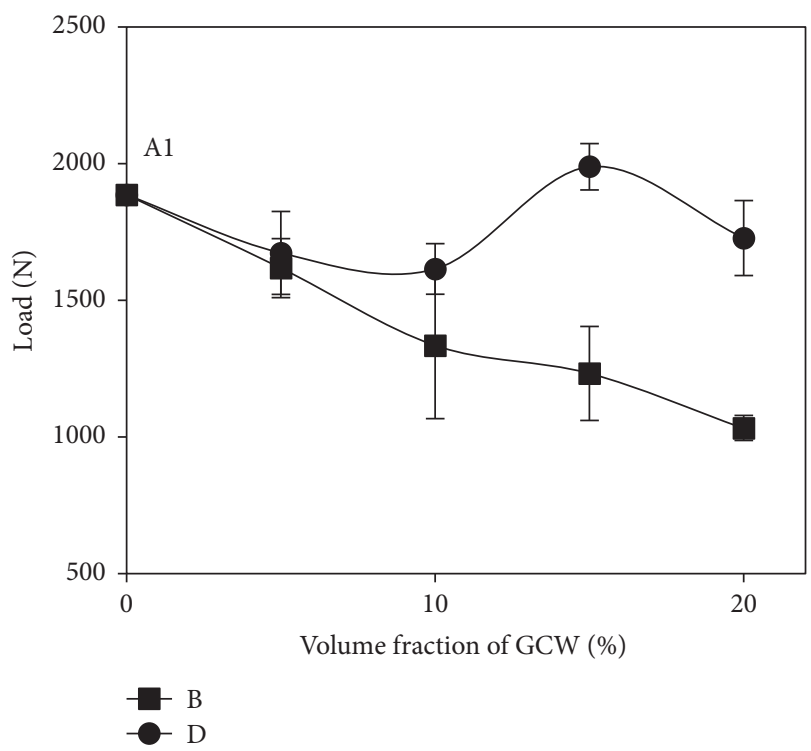

(a)

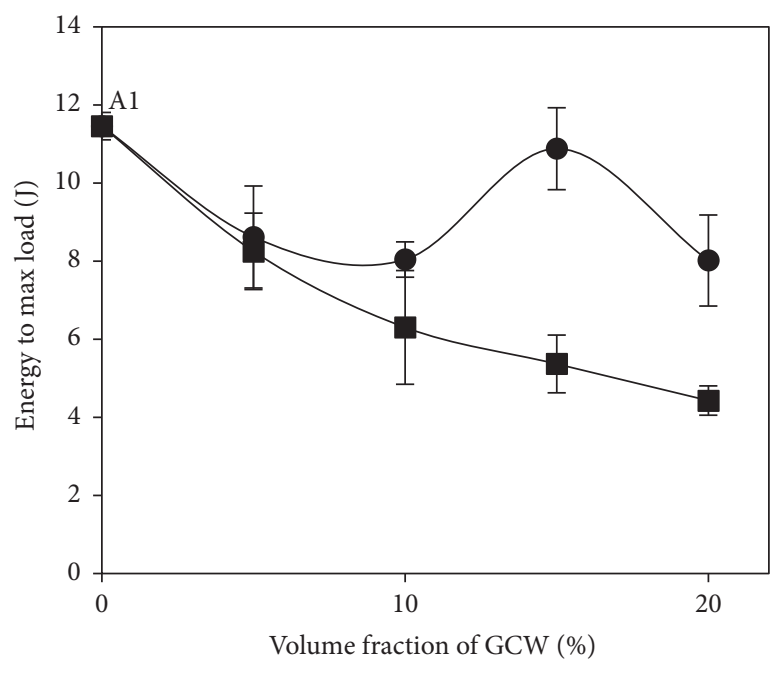

(b)

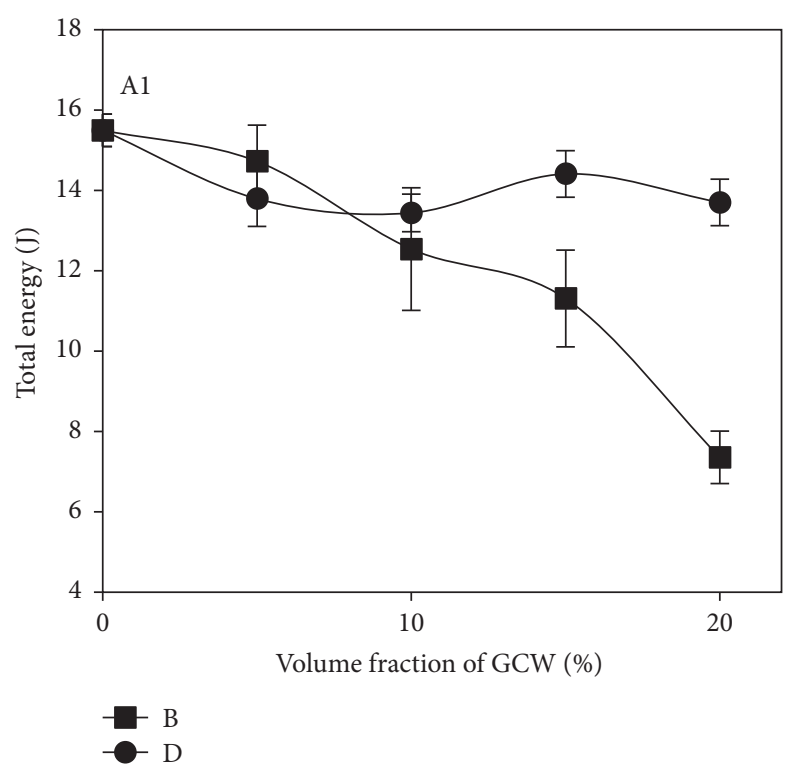

(c)

Figure 9: Effect of volume fraction of GCW on (a) load; (b) energy to maximum load; (c) total energy of composites types B and D.

for interaction, thus, providing better stress transfer. Similar trend of improvement of impact properties using alkaline treatment done by other researcher [18].

3.7. Water Absorption. The water absorption was conducted for 30 days. Figure 12 represents the percentage weight gain as a function of the square root of time in seconds. As observed in Figure 12(a), the weight gain percentage of the composites increased with increasing immersion time. In addition, percentage weight gain of composite type B increased with volume fraction for $0.05 \%, 1.7 \%, 5.2 \%, 7.2 \%$, and $10.3 \%$. This was a consequence of hydrophilic nature of untreated GCW particles. Figure 12(b) shows that composite type $\mathrm{D} 2$ was having weight gain of $2.2 \%$. It was $57 \%$ reduction in water absorption compared to composite type B. This has shown that alkaline treatment is able to increase the hydrophobicity of the GCW.

\section{Conclusion}

The structural, thermal, and mechanical properties of the GCW/oxo-HDPE biocomposites for different fiber content $(5 \%, 10 \% 15 \%$, and $20 \%)$ were studied as a function of alkaline treatment. The performance of treated GCW composite exhibited better characteristics than untreated GCW composite. Optimized result obtained when using $10 \%$ volume fraction GCW for tensile properties and 15\% volume fraction for impact properties. Alkaline treatment had successfully 


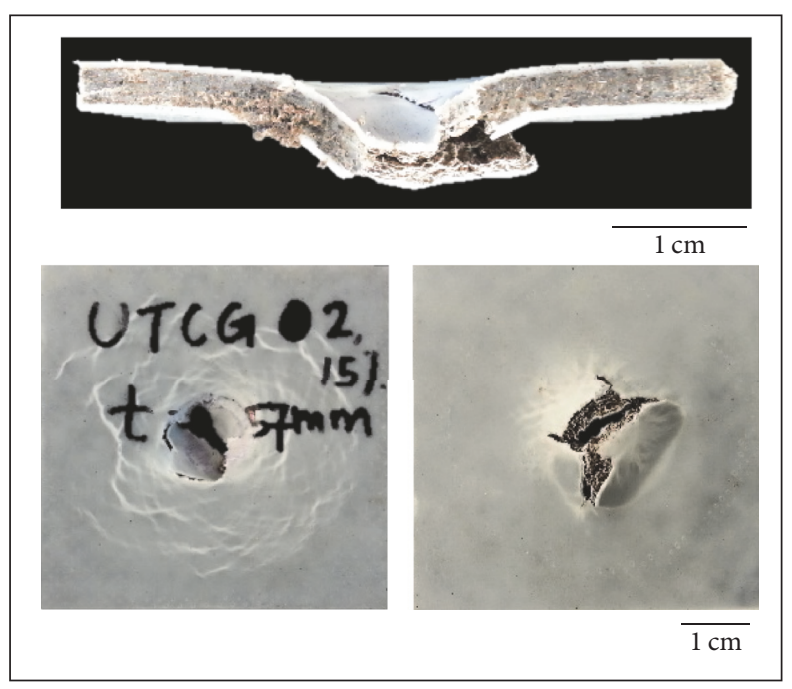

(a)

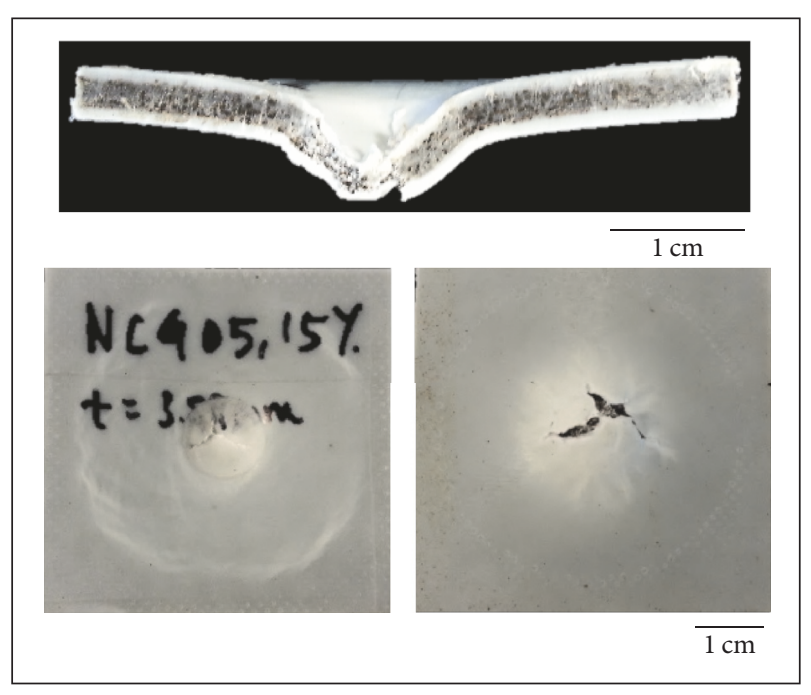

(b)

FIGURE 10: Fracture surface of impact test: (a) composite type B3 and (b) composite type D3.

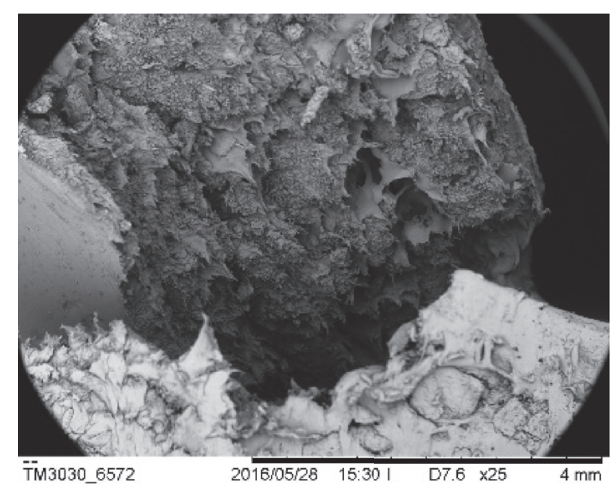

(a)

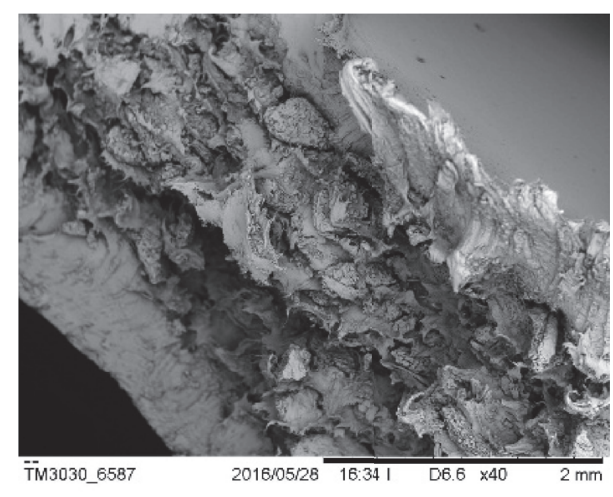

(b)

FIGURE 11: SEM pictograph of fracture surface of impact test: (a) composite type B3 and (b) composite type D3.

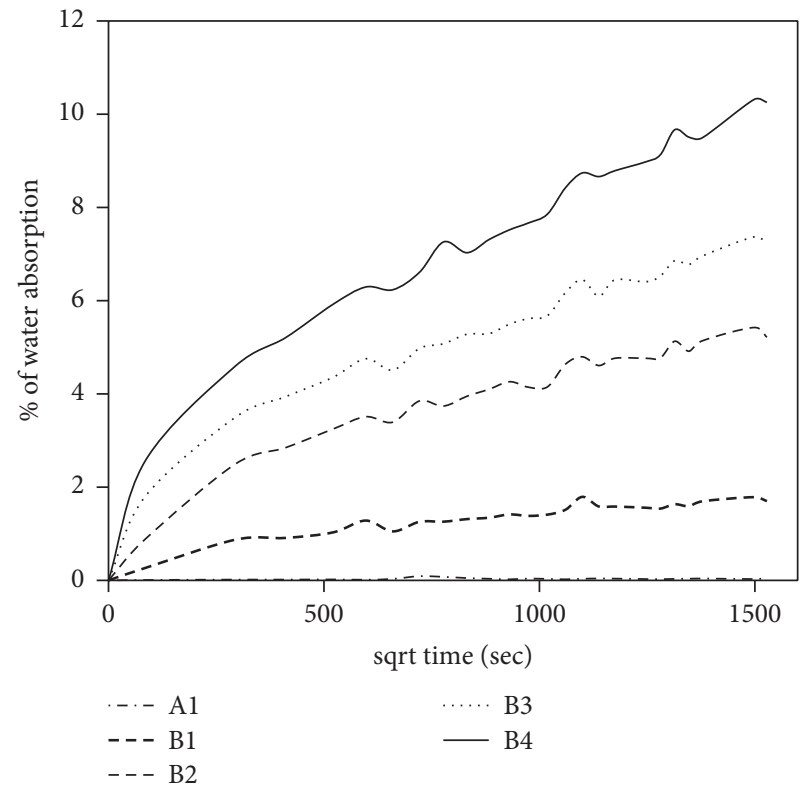

(a)

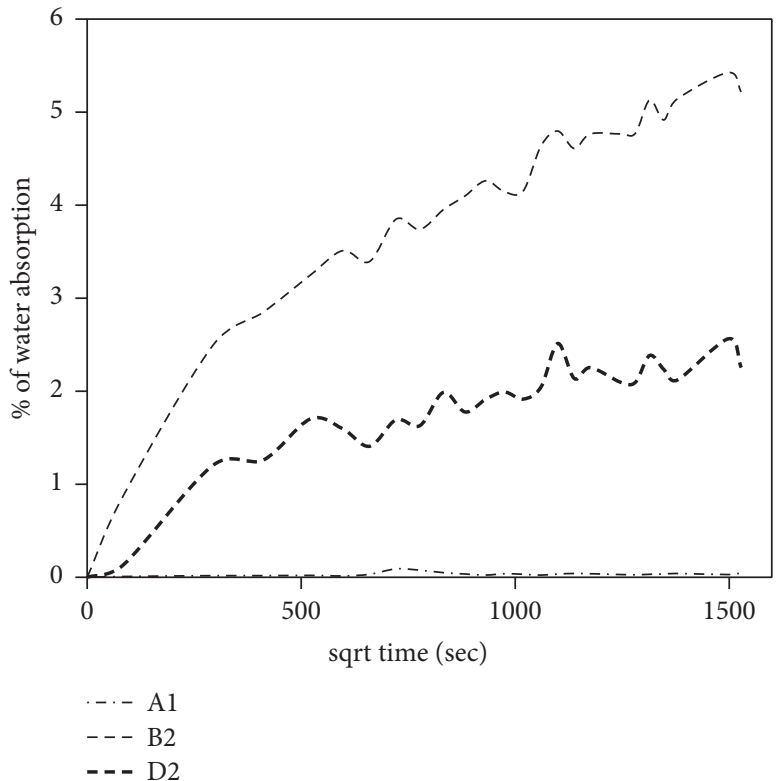

(b)

FIGURE 12: Percent mass gain due to the absorption of water for (a) composites types A and B; (b) composites types A1, B2, and D2. 
improved the properties of the composites. This is proven by the removal of unwanted impurities which improved thermal stability and degree of crystallinity, while creating better water resistance and enhanced mechanical properties towards the composite. The outcome of present work shows that this particular type of composite has the potential in many composite engineering applications, such as automotive, packaging, and lightweight furniture.

\section{Conflicts of Interest}

The authors declare that there are no conflicts of interest regarding the publication of this paper.

\section{Acknowledgments}

The authors gratefully acknowledge University Malaysia Sarawak for providing the opportunity and support to conduct this research and MOHE for funding the project through FRGS Grant (FRGS/TK04(01)/1081/2013(27)).

\section{References}

[1] T. Tokimoto, N. Kawasaki, T. Nakamura, J. Akutagawa, and S. Tanada, "Removal of lead ions in drinking water by coffee grounds as vegetable biomass," Journal of Colloid and Interface Science, vol. 281, no. 1, pp. 56-61, 2005.

[2] International Coffee Organization, "Coffee consumption in East and Southeast Asia: 1990-2012," 2014.

[3] D. Pujol, C. Liu, J. Gominho et al., "The chemical composition of exhausted coffee waste," Industrial Crops and Products, vol. 50, pp. 423-429, 2013.

[4] N. S. Caetano, V. F. M. Silvaa, and T. M. Mata, "Valorization of coffee grounds for biodiesel production," Chemical Engineering Transactions, vol. 26, pp. 267-272, 2012.

[5] S. I. Mussatto, L. M. Carneiro, J. P. A. Silva, I. C. Roberto, and J. A. Teixeira, "A study on chemical constituents and sugars extraction from spent coffee grounds," Carbohydrate Polymers, vol. 83, no. 2, pp. 368-374, 2011.

[6] K. Kante, C. Nieto-Delgado, J. R. Rangel-Mendez, and T. J. Bandosz, "Spent coffee-based activated carbon: Specific surface features and their importance for $\mathrm{H} 2 \mathrm{~S}$ separation process," Journal of Hazardous Materials, vol. 201-202, pp. 141-147, 2012.

[7] W. Tsai, S. Liu, and C. Hsieh, "Preparation and fuel properties of biochars from the pyrolysis of exhausted coffee residue," Journal of Analytical and Applied Pyrolysis, vol. 93, pp. 63-67, 2012.

[8] D. C. Preethu, B. N. U. H. Prakash, C. A. Srinivasamerthy, and B. G. Vasanthi, "Maturity indeces as in index to evaluate the quality of compost of coffee waste blended with other organic wastes," in Proceddings of the International Conference on Sustainable Solid Waste Management, pp. 270-275, 2007.

[9] M. Tasdemir, H. Biltekin, and G. T. Caneba, "Re-use of Exhausted Ground Coffee Waste for Cr(VI) Sorption," Journal of Applied Polymer Science, vol. 43, no. 3, pp. 582-596, 2008.

[10] B.-S. Baek, J.-W. Park, B.-H. Lee, and H.-J. Kim, "Development and application of green composites: using coffee ground and bamboo flour," Journal of Polymers and the Environment, vol. 21, no. 3, pp. 702-709, 2013.
[11] C.-S. Wu, "Renewable resource-based green composites of surface-treated spent coffee grounds and polylactide: characterisation and biodegradability," Polymer Degradation and Stability, vol. 121, pp. 51-59, 2015.

[12] M. Y. Tan, H. T. N. Kuan, and A. A. Khan, "Tensile properties of ground coffee waste reinforced polyethylene composite," Materials Science Forum, vol. 880, pp. 73-76, 2017.

[13] S. M. Aboul-Fadl, S. H. Zeronian, M. M. Kamal, M. S. Kim, and M. S. Ellison, "Effect of mercerization on the relation between single fiber mechanical properties and fine structure for different cotton species," Textile Research Journal, vol. 55, no. 8, pp. 461-469, 1985.

[14] F. Z. Arrakhiz, M. Malha, R. Bouhfid, K. Benmoussa, and A. Qaiss, "Tensile, flexural and torsional properties of chemically treated alfa, coir and bagasse reinforced polypropylene," Composites Part B: Engineering, vol. 47, pp. 35-41, 2013.

[15] S. L. Fávaro, M. S. Lopes, A. G. V. D. C. Neto, R. R. de Santana, and E. Radovanovic, "Chemical, morphological, and mechanical analysis of rice husk/post-consumer polyethylene composites," Composites Part A: Applied Science and Manufacturing, vol. 41, no. 1, pp. 154-160, 2010.

[16] K. Anbukarasi and S. Kalaiselvam, "Study of effect of fibre volume and dimension on mechanical, thermal, and water absorption behaviour of luffa reinforced epoxy composites," Materials and Design, vol. 66, pp. 321-330, 2015.

[17] A. S. Singha, A. K. Rana, and R. K. Jarial, "Mechanical, dielectric and thermal properties of Grewia optiva fibers reinforced unsaturated polyester matrix based composites," Materials and Design, vol. 51, pp. 924-934, 2013.

[18] H. Obasi, N. C. Iheaturu, F. Onuoha, M. N. Akanbi, and V. O. Ezeh, "Influence of Alkali treatment and fibre content on the properties of oil palm press fibre reinforced epoxy biocomposites," American Journal of Engineering Research, vol. 3, no. 2, pp. 117-123, 2014.

[19] C. Sibele Piedade and M. Luis Claudio, "Thermal properties and morphology of high-density polyethylene filled with coffee dregs," Journal of Thermal Analysis and Calorimetry, vol. 114, no. 1, pp. 1-4, 2013.

[20] ASTM D3039/D3039M, Standard Test Method for Tensile Properties of Polymer Matrix Composite Materials, 2000.

[21] ASTM D3763, ASTM D3763: Standard Test Method for High Speed Puncture Properties of Plastics Using Load and Displacement Sensors, 2012.

[22] ASTM D570-98, ASTM D570-10: Standard Test Method for Water absorption of Plastics, 2010.

[23] V. K. Varshney and S. Naithani, Cellulose Fibers: Bio- and NanoPolymer Composites, Springer, Berlin, Germany, 2011.

[24] T. Kondo, "Hydrogen bonds in cellulose and cellulose derivatives," in Structural Diversity and Functional Versatility, S. Dumitriu, Ed., CRC Press, New York, NY, USA, 2nd edition, 2004.

[25] E. K. Kemsley, S. Ruault, and R. H. Wilson, "Discrimination between Coffea arabica and Coffea canephora variant robusta beans using infrared spectroscopy," Food Chemistry, vol. 54, no. 3, pp. 321-326, 1995.

[26] N. Reis, A. S. Franca, and L. S. Oliveira, "Discrimination between roasted coffee, roasted corn and coffee husks by diffuse reflectance infrared fourier transform spectroscopy," LWT-Food Science and Technology, vol. 50, no. 2, pp. 715-722, 2013. 
[27] A. P. Craig, A. S. Franca, and L. S. Oliveira, "Evaluation of the potential of FTIR and chemometrics for separation between defective and non-defective coffees," Food Chemistry, vol. 132, no. 3, pp. 1368-1374, 2012.

[28] M. M. Paradkar and J. Irudayaraj, "Rapid determination of caffeine content in soft drinks using FTIR-ATR spectroscopy," Food Chemistry, vol. 78, no. 2, pp. 261-266, 2002.

[29] D. R. Cremer and G. Kaletunç, "Fourier transform infrared microspectroscopic study of the chemical microstructure of corn and oat flour-based extrudates," Carbohydrate Polymers, vol. 52, no. 1, pp. 53-65, 2003.

[30] L. M. Matuana, J. J. Balatinecz, R. N. S. Sodhi, and C. B. Park, "Surface characterization of esterified cellulosic fibers by XPS and FTIR spectroscopy," Wood Science and Technology, vol. 35, no. 3, pp. 191-201, 2001.

[31] H. D. Nguyen, T. T. Thuy Mai, N. B. Nguyen, T. D. Dang, M. L. Phung Le, and T. T. Dang, "A novel method for preparing microfibrillated cellulose from bamboo fibers," Advances in Natural Sciences: Nanoscience and Nanotechnology, vol. 4, no. 1, article 015016, 2013.

[32] T. Nguyen, E. Zavarin, and E. M. Barrall, “Thermal analysis of lignocellulosic materials. Part II. modified materials," Journal of Macromolecular Science, Part C, vol. 21, no. 1, pp. 1-60, 2007.

[33] F. Kifani-Sahban, L. Belkbir, and A. Zoulalian, "Study of the slow pyrolysis of Moroccan eucalyptus by thermal analysis," Thermochimica Acta, vol. 284, no. 2, pp. 341-349, 1996.

[34] M. Le Troëdec, A. Rachini, C. Peyratout et al., "Influence of chemical treatments on adhesion properties of hemp fibres," Journal of Colloid and Interface Science, vol. 356, no. 1, pp. 303310, 2011.

[35] A. K. Bledzki and J. Gassan, "Composites reinforced with cellulose based fibres," Progress in Polymer Science, vol. 24, no. 2, pp. 221-274, 1999.

[36] A. Valadez-Gonzalez, J. M. Cervantes-Uc, R. Olayo, and P. J. Herrera-Franco, "Effect of fiber surface treatment on the fibermatrix bond strength of natural fiber reinforced composites," Composites B: Engineering, vol. 30, no. 3, pp. 309-320, 1999.

[37] H. D. Rozman, H. Ismail, R. M. Jaffri, A. Aminullah, and Z. A. M. Ishak, "Mechanical properties of polyethylene-oil palm empty fruit bunch composites," Polymer-Plastics Technology and Engineering, vol. 37, no. 4, pp. 495-507, 1998.

[38] N. M. Stark and R. E. Rowlands, "Effects of wood fiber characteristics on mechanical properties of wood/polypropylene composites," Wood and Fiber Science, vol. 35, no. 2, pp. 167-174, 2003.

[39] S. K. De and J. R. White, Short fibre polymer composite, Woodhead Publishing Limited, Cambridge, UK, 1996.

[40] H.-S. Yang, M. P. Wolcott, H.-S. Kim, S. Kim, and H.-J. Kim, "Effect of different compatibilizing agents on the mechanical properties of lignocellulosic material filled polyethylene biocomposites," Composite Structures, vol. 79, no. 3, pp. 369-375, 2007. 

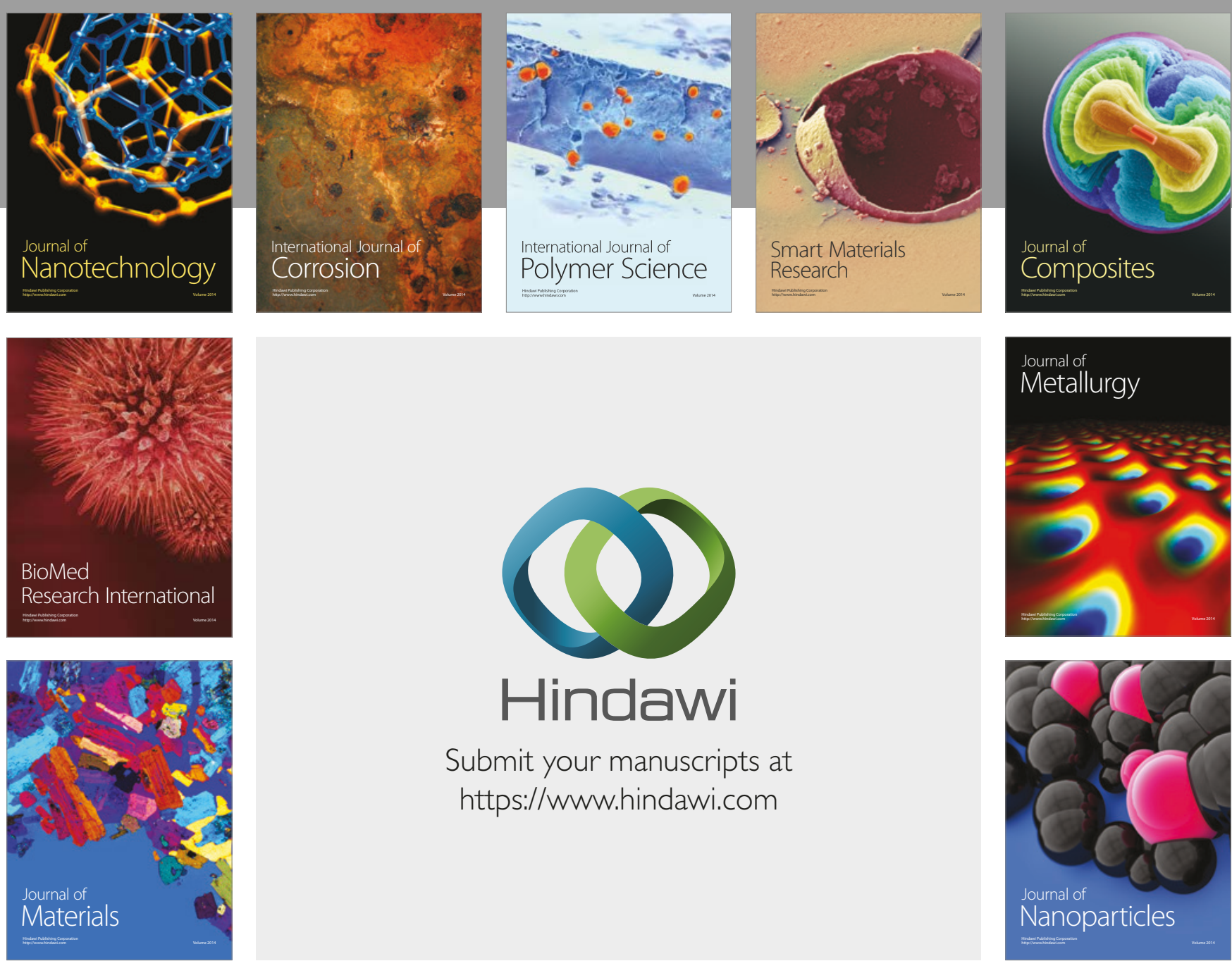

\section{Hindawi}

Submit your manuscripts at

https://www.hindawi.com
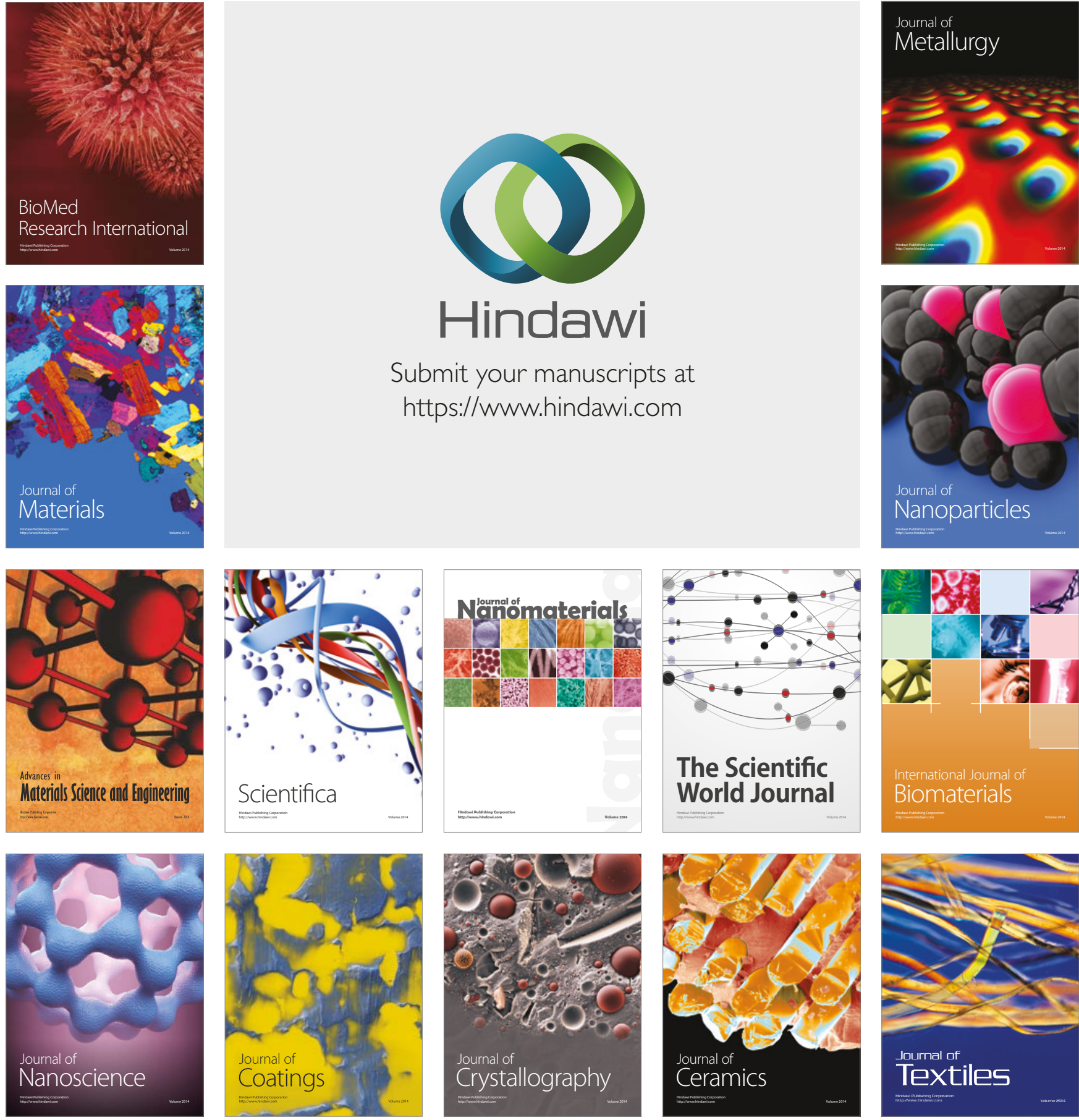

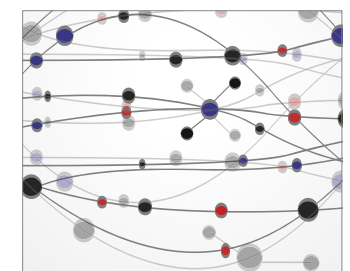

The Scientific World Journal
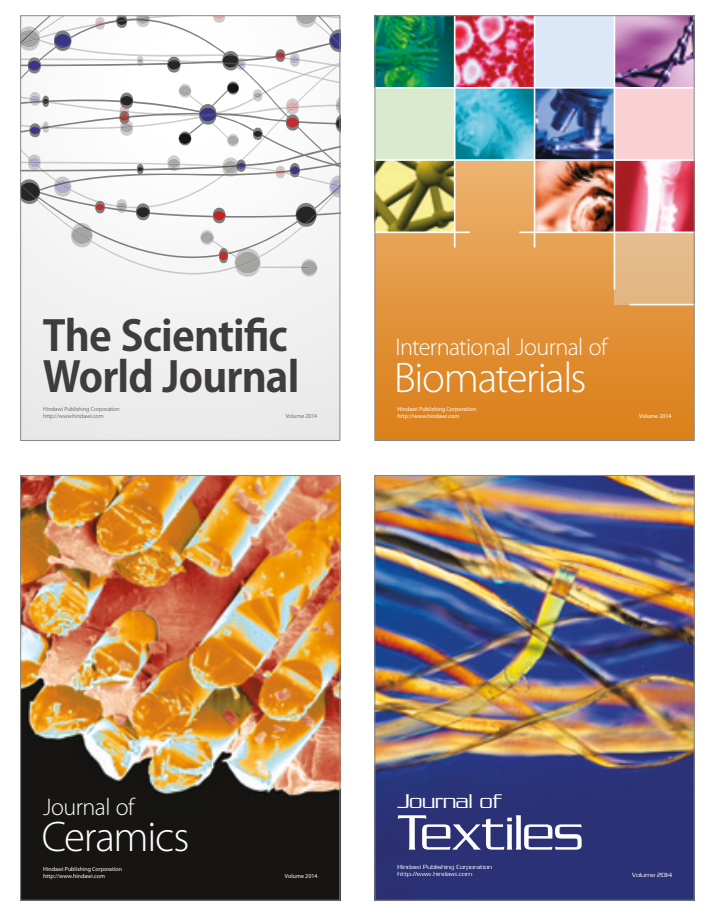